\title{
Dementia reversible by plasmapheresis in multiple myeloma
}

\author{
I. Guldenschuh', R. Schiess², E. Jacky', J. Burger ${ }^{1}$ and T. Landis² \\ Departments of ${ }^{1}$ Internal Medicine and ${ }^{2}$ Neurology, University Hospital Zürich, Switzerland \\ Correspondence to: T. Landis, Neurologische Klinik, Universitätsspital, CH-8091 Zürich, \\ Switzerland
}

\begin{abstract}
Although hyperviscosity syndrome may lead to cerebral hypoxia and produce some degree of dementia, this condition is rarely recogniżed. We report a patient in whom moderate dementia was the only manifestation of a hyperviscosity syndrome due to an IgG- $\kappa$ myeloma. Dementia dramatically improved following plasmapheresis.
\end{abstract}

Keywords: Dementia - Hyperviscosity - Plasmapheresis

\section{INTRODUCTION}

Among the many dementing diseases (Cummings and Benson, 1992), clinically of greatest importance are those in which dementia is potentially reversible (Cummings $e t$ al., 1980). A condition which can cause reversible cerebral hypoxia is hyperviscosity syndrome (HVS) as occurring in Waldenstroem's macroglobulinaemia (Waldenström, 1944), hyperlipidaemia (Heilman and Fisher, 1974), leukaemia (Preston et al., 1978), multiple myeloma (Mueller et al., 1983), etc. HVS includes bleeding from mucosal membranes, retinopathy, congestive heart failure and a broad spectrum of neurological symptoms. Although HVS is not uncommon, dementia as a leading symptom is rarely described (Mueller et al., 1983).

\section{CASE REPORT}

This 67-year-old housewife had an uneventful medical history until one year ago when she started suffering from pain in the lumbar and thoracic region and from nocturnal sweating. On admission complete medical and neurological examinations were normal and remained normal throughout the course of the illness. In particular there was no mucosal membrane bleeding, nor abnormalities of the fundus or hearing. Mental status at admission revealed minimal difficulties with short-term memory and word finding. A diagnosis of multiple myeloma of the IgG- $\kappa$ type was made on the basis of multiple osteolytic lesions in the skull and spine together with laboratory data: BSR 110 $\mathrm{mm} / \mathrm{h}$, bone marrow infiltration of $23 \%$ plasma cells, haemoglobin $8.5 \mathrm{~g} \%$, haematocrit $27.2 \%$, total protein 156 $\mathrm{g} / 1$ (normal 65-80 g/1), serum globulins $114 \mathrm{~g} / \mathrm{l}(35-40 \mathrm{~g} / \mathrm{l})$, albumin $38.5 \mathrm{~g} / \mathrm{l}(35-50 \mathrm{~g} / \mathrm{l})$. Serum immunoelectrophoresis demonstrated IgG- $\kappa$ monoclonal gammopathy of the $\mathrm{IgG}_{1}$ subclass of $74.5 \mathrm{~g} / 1$ (normal 7-19 $\mathrm{g} / \mathrm{l}$ ), IgA of less than $0.3 \mathrm{~g} / \mathrm{l}(0.7-4.0 \mathrm{~g} / \mathrm{l})$ and $\mathrm{IgM}$ of less than $0.3 \mathrm{~g} / 1(0.6-2.8$ $\mathrm{g} / \mathrm{l})$. The plasma viscosity could not be directly measured, but was estimated to be between $5 \mathrm{cp}$ [according to the linear correlation between monoclonal protein concentration and plasma viscosity described by Crawford et al. (1985)] and $8 \mathrm{cp}$ [according to the averaged viscosity values described by Pruzanski and Watt (1972)] (normal $1.62 \pm 0.05 \mathrm{cp}$ ). All other laboratory data were normal.

Between Days 2 and 7 in hospital chemotherapy with melphalan $15 \mathrm{mg} /$ day and prednisone $100 \mathrm{mg} /$ day orally was performed. She did not suffer any adverse effect of chemotherapy, but deteriorated during the first 2 weeks in hospital, became disorientated and lethargic, and developed mild paranoid ideation. CT scan of the head was normal and ${ }^{99 m}$ Tc-HMPAO-SPECT did not show areas of focal hypoperfusion, but EEG was abnormal with a diffuse slowing in the theta and delta range with repeated occurrence of bi- and triphasic wave complexes with frontal accentuation. CSF was normal.

Comprehensive neuropsychological examination at Day 15 in hospital revealed a picture of marked subcortical dementia (Cummings, 1990) with severe impairment of learning and recall in the presence of mild deficits of recognition memory, strongly impaired figural and verbal 
fluency, difficulties with concept identification and interference suppression and an altered affect with some depressive and paranoid components. There were no signs of aphasia, apraxia or agnosia, but some word finding difficulties.

Plasmapheresis was started at Day 19. On two consecutive days 2.31 plasma were exchanged. The paraprotein fell to $27 \mathrm{~g} / \mathrm{l}$ (less than $50 \%$ of the initial value). This resulted within $24 \mathrm{~h}$ in a dramatic improvement of her mental status. She became more alert, completely orientated in time and space and memory functions improved. After an interval of 2 days plasmapheresis of 2.31 was twice more performed, without further clinical improvement. At Day 25 she was given another course of chemotherapy consisting of $100 \mathrm{mg} /$ day prednisone and $15 \mathrm{mg} /$ day melphalan over 5 days, during which the paraprotein rose and the patient again showed signs of increased apathy, slowness in thinking and a lack of spontaneity. At Day 37 this decline in mental status prompted plasmapheresis on two following days, which resulted in an immediate restoration of the mental state observed after the initial plasmapheresis. The EEG normalized. Neuropsychological examination on the day of the last plasmapheresis had normalized except for a minimally impaired recognition memory and some paranoid ideation. One month after discharge neuropsychological examination was entirely normal.

\section{DISCUSSION}

We have presented a patient in whom a marked subcortical dementia of subacute onset was the only manifestation of HVS in an IgG-K myeloma. After plasmapheresis the dementia cleared dramatically. A second course of plasmapheresis was necessary when dementia recurred together with a rise of paraprotein, probably due to a washout from extracellular fluid compartments. Following the second plasmapheresis the patient returned to her normal state and has remained symptom-free for the past 6 months.

HVS is common in a wide variety of diseases (Waldenström, 1944; Heilman and Fisher, 1974; Preston et al., 1978; Mueller et al., 1983). Its frequency in IgA and IgG myelomas is estimated at $10 \%$ and $4 \%$, respectively.
Although neurological deficits such as hemiparesis, lethargy, coma, seizures or acute confusional states are not infrequent in HVS, dementia is uncommon, particularly as isolated as in the present case. This is surprising, since generalized but mild cerebral hypoxia, as expected to occur by hypoperfusion due to HVS, quite early leads to disturbances in memory and frontal lobe functions when encountered in other mild to moderately hypoxic conditions, such as exposure to high altitude (Regard et al., 1989). Thus the observation of mild to moderate subcortical dementia in diseases known to produce HVS should alert the clinician, particularly since this condition is potentially reversible by plasmapheresis.

\section{Acknowledgement}

This work has in part been supported by the Swiss National Science Foundation grant 32-31260.91.

\section{REFERENCES}

Crawford J, Cox EB and Cohen HJ (1985) Evaluation of hyperviscosity in monoclonal gammopathies. American Journal of Medicine, 79, 13-21.

Cummings JL (1990) Subcortical Dementia. Oxford University Press, Oxford.

Cummings JL and Benson DF (1992) Dementia: A Clinical Approach, 2nd edn. Butterworth-Heinemann, Boston.

Cummings JL, Benson DF and LoVerme S (1980) Reversible dementia: illustrative cases, definition, and review. Journal of the American Medical Association, 243, 2434-2439.

Heilman KM and Fisher WR (1974) Hyperlipidemic dementia. Archives of Neurology, 31, 67-68.

Mueller J, Hotson JR and Langston JW (1983) Hyperviscosity induced dementia. Neurology, 33, 101-103.

Preston FE, Cooke KB, Foster ME, Winfield DA and Lee D (1978) Myelomatosis and the hyperviscosity syndrome. British Journal of Haematology, 38, 517-530.

Pruzanski W and Watt JG (1972) Serum viscosity and hyperviscosity syndrome in IgG multiple myeloma. Annals of Internal Medicine, 77, 853-860.

Regard M, Oelz O, Brugger P and Landis T (1989) Persistent cognitive impairment in climbers after repeated exposure to extreme altitude. Neurology, 39, 210-213.

Waldenström J (1944) Incipient myelomatosis or "essential" hyperglobulinemia with fibrogenopenia: a new syndrome? Acta Medica Scandinavica, 117, 216.

(Received 12 July 1993; accepted 8 August 1993) 


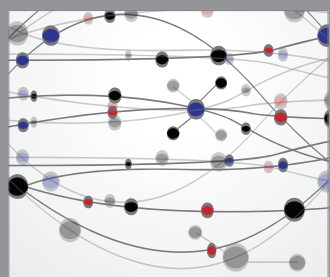

The Scientific World Journal
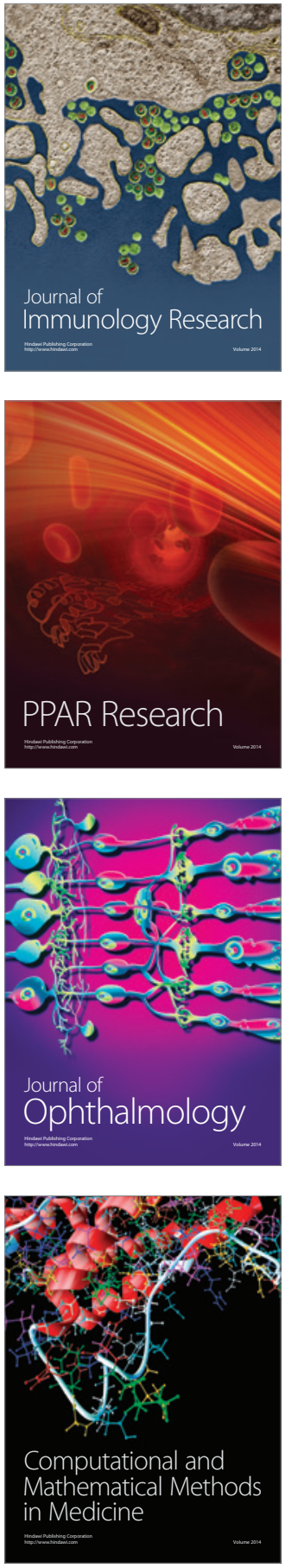

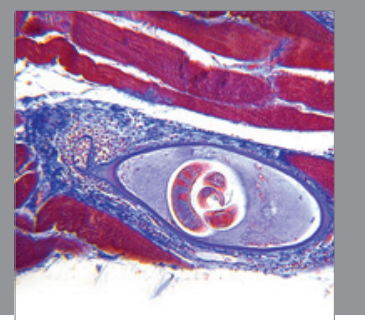

Gastroenterology

Research and Practice
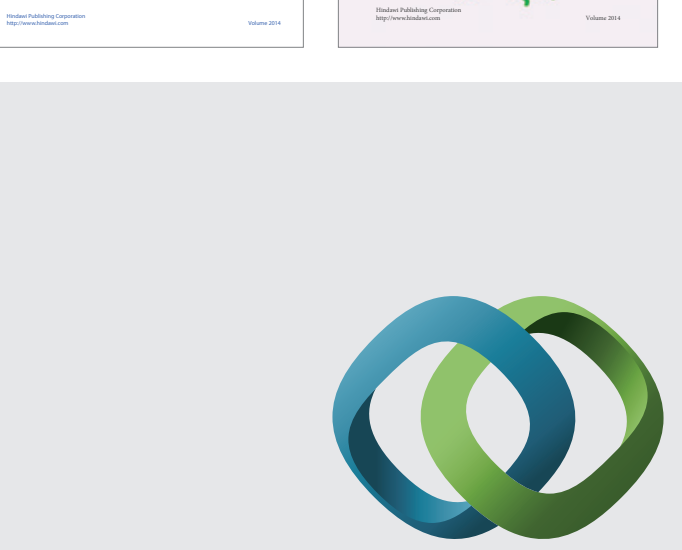

\section{Hindawi}

Submit your manuscripts at

http://www.hindawi.com
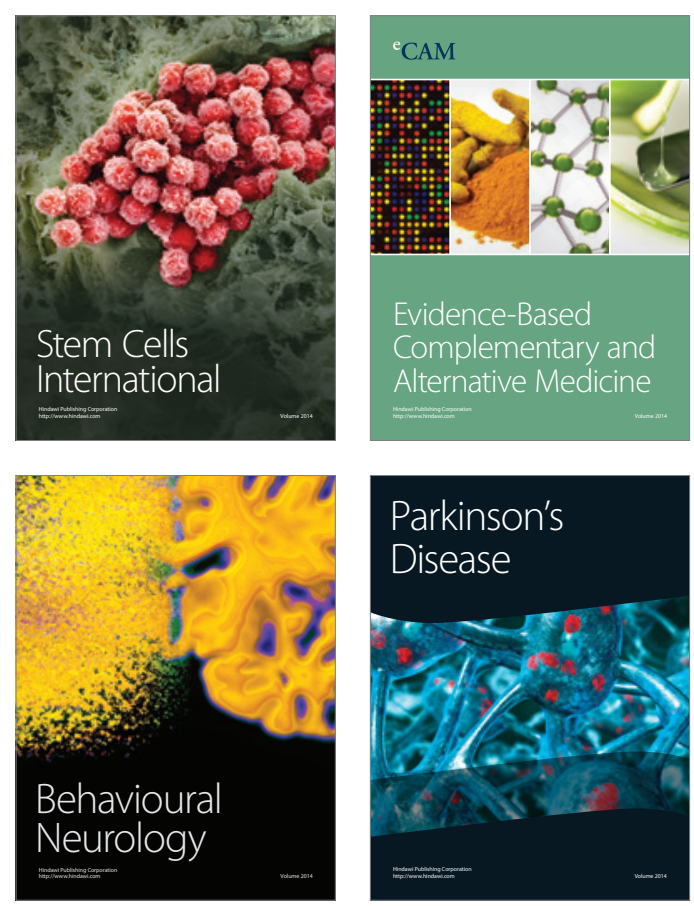

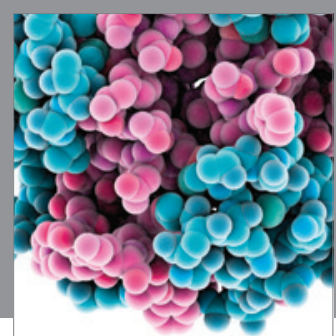

Journal of
Diabetes Research

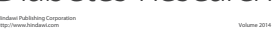

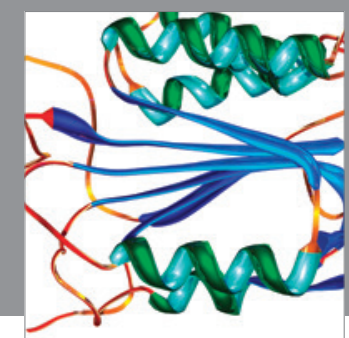

Disease Markers
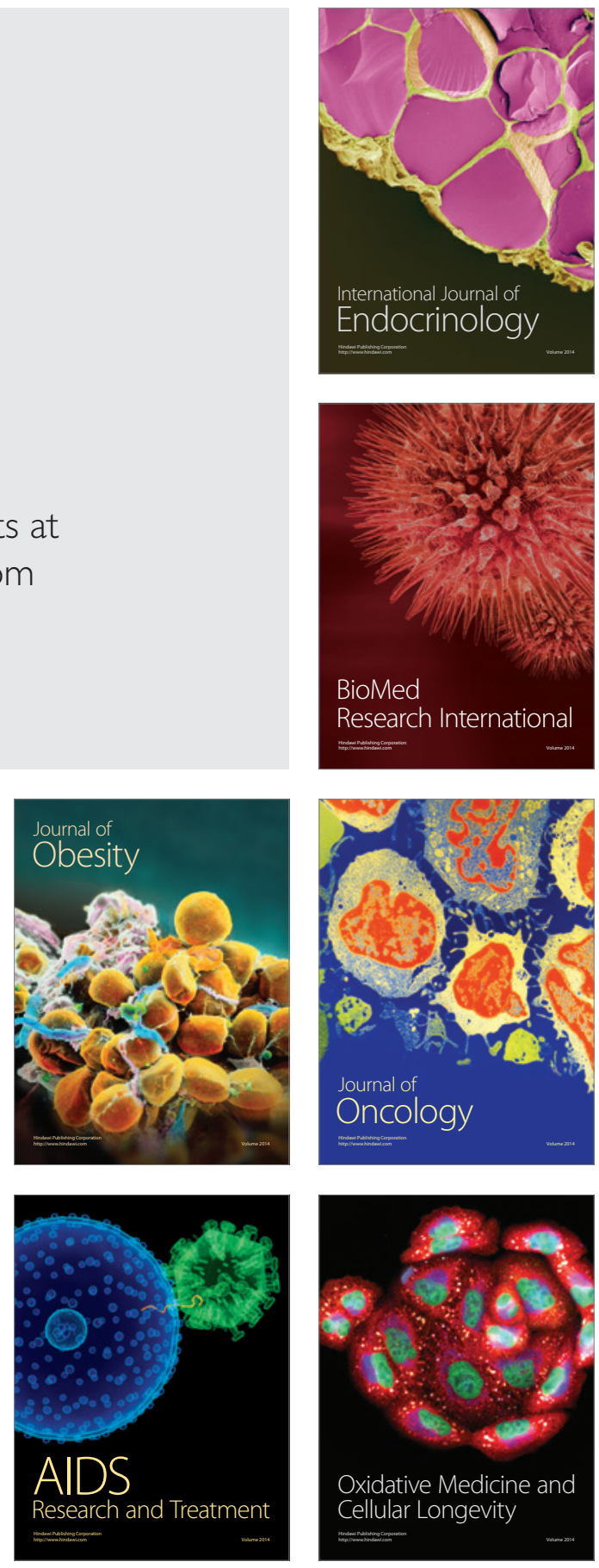